\title{
Performance Analysis of Different Control Strategies in a Z-source Inverter
}

\author{
Byamakesh Nayak \\ School of Electrical Engineering \\ KIIT University, Bhubaneswar \\ Orissa, India \\ electricbkn11@gmail.com
}

\author{
Saswati Swapna Dash \\ Dpt of Electrical Engineering \\ YMCA University of Science \& Tech. \\ Faridabad, Haryana, India \\ reachtoswapna@gmail.com
}

\begin{abstract}
This paper presents the analysis for different control techniques in $Z$-source inverters. The voltage gain versus modulation index from simulation result is compared with the mathematical calculated voltage gain. Further detailed analysis of \% THD, \%harmonics of output voltage at different modulation indexes for different boosting techniques of a $\mathrm{Z}$-source inverter are also performed with respect to the traditional VSI by MATLAB based simulation.
\end{abstract}

Keywords- Z-source inverter; shoot through; boost factor; voltage gain; voltage stress; total harmonic distortion (THD)

\section{INTRODUCTION}

Conventionally two types of three phase inverters are used, the voltage source inverter (VSI) and the current source inverter (CSI). In VSI, a capacitor is used in a DC link to obtain a constant voltage source and in CSI a large inductor is used to obtain a constant current source. These inverters have certain limitations. Commonly used Pulse Width Modulated (PWM) VSI is used for buck (step down) DC to AC power conversion. An additional DC-DC boost converter is needed to boost the AC voltage output. The CSI is used as a boost inverter in $\mathrm{DC}$ to $\mathrm{AC}$ conversion. For a change in voltage range, it also requires additional buck (or boost) DC-DC converters. Hence, no traditional inverter can be employed solely for buck and boost simultaneously, without additional DC link converters.

To overcome the drawbacks of traditional inverters, the newly proposed impedance source or Z-source inverter [1] can be used, which is virtually the combination of VSI and CSI. It employs an impedance network as a DC link consisting of L and $\mathrm{C}$ to couple the converter bridge and the power source as shown in Figure 1.

A traditional PWM 3-phase VSI operates in eight states, six active and two null states. In active states, power is transported from the DC link to the AC output, whereas in null states the DC link capacitor is charged from the DC source. The shootthrough state is introduced within the null state of Z-source inverter. This cannot be applied in voltage source inverter. The shoot-through state in Z-source inverter enhances the voltage at the load end. It should be inserted in such a way that, equal null intervals are again maintained at the start and end of the switching cycle, to achieve the same optimal harmonic performance.

This paper represents the comparison of voltage gain, $\%$ THD and \%harmonics at different modulation indexes using different boosting techniques, in Z-source inverter. The boosting techniques for the Z-source inverter used in this paper are the simple boost control, the maximum boost control, the $3^{\text {rd }}$ harmonic injected constant boost control and the $3^{\text {rd }}$ harmonic injected maximum boost control method.

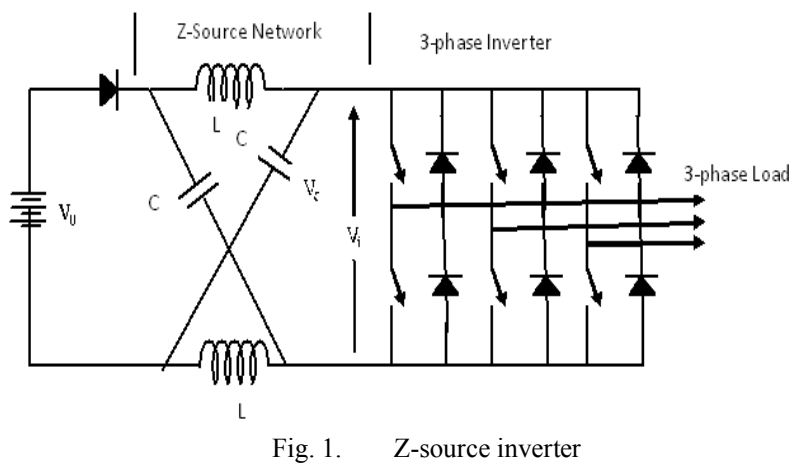

II. CONTROL TECHNIQUES

\section{A. Simple boost control}

In the sinusoidal PWM inverter, the gate pulses are obtained by comparing the 3-phase balanced sinusoidal carrier signals with triangular carrier signals. The drawback of the method is that it cannot be used for boosting of the output voltage because of the two null states in addition to the six active states in one cycle of operations. The shoot-through should be introduced in null states by various techniques as discussed in [1-2] to boost the output voltage. The shootthrough techniques are objectionable in sinusoidal PWM voltage source inverter. The shoot-through can be inserted in null-state if Z-source is incorporated between the input DC voltage and the VSI inverter power circuit as shown in Figure 1. In the VSI switching cycle, the zero state is produced when all sinusoidal waveforms are less or greater than the carrier signal. Therefore, to provide shoot-through in zero state the 
other two steady signals $\left(V_{p}, V_{n}\right)$ whose amplitudes are equal to the amplitude of the sinusoidal waveform and the one is the negative of the other, are compared with triangular signal as shown in Figure 2. As discussed in [1-2] the shoot through states are obtained in all three legs at a time, maintaining shoot through time per switching cycle as constant. The gate pulses for the simple boost method are shown in Figure 2. The voltage gain in simple constant boost ZSI is expressed as:

$G=M B=\frac{\hat{V}_{a c}}{V_{o} / 2}$

where $\hat{V}_{a c}$ is the output peak phase voltage, $\mathrm{V}_{\mathrm{o}}$ is the input DC voltage, $\mathrm{M}$ is the modulation index and $\mathrm{B}$ is the boost factor.

The boost factor is determined by following expression:

$$
B=\frac{1}{1-2 T_{0} / T}
$$

where $T_{o}$ is the shoot-through time interval over a switching period $T$. The duty ratio $\left(T_{0} / T\right)$ decreases with the increase of $M$ in shoot-through state.

Thus the voltage gain can be expressed as:

$$
G=M B=\frac{\hat{V}_{a c}}{V_{o} / 2}=\frac{M}{2 M-1}
$$

Voltage stress [2] is given by:

$$
V_{s}=B V_{o}=(2 G-1) V_{o}
$$

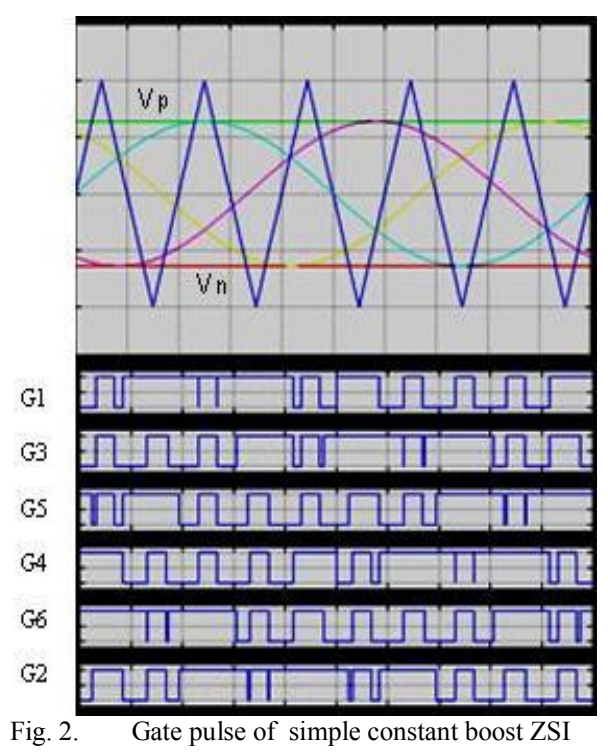

Voltage stress in switches increases as the voltage gain increases. So, this control method cannot be implemented to obtain higher gain because of the limitation of voltage ratings of switches. Therefore, other suitable control techniques can be adopted to operate the Z-source inverter at higher gains.

\section{B. Maximum boost control}

Voltage stress is minimized on switches by maximizing $T_{o}$ and $B$ for a given modulation index. Considering the previous method, a simple modification is required. The shoot-through state is achieved when the triangular carrier wave is either greater than the maximum curve of three sinusoidal references or smaller than the minimum of the references [2]. Figure 3 depicts the gate pulse for six switches.

Averaging of the varying shoot-through times, the boost factor, voltage gain and voltage stress are given by the following equations:

$$
\begin{aligned}
& B=\frac{1}{1-2 T_{o} / T}=\frac{\pi}{3 \sqrt{3} M-\pi} \\
& G=M B=\frac{\hat{V}_{a c}}{V_{o} / 2}=\frac{\pi M}{3 \sqrt{3} M-\pi} \\
& V_{s}=B V_{o}=\frac{3 \sqrt{3} G-\pi}{\pi} V_{o}
\end{aligned}
$$

The voltage stress is much lower in comparison to the simple boost control. Hence, the inverter can be operated at a higher voltage gain.

\section{Third harmonic injection control}

This method is opted to use the increased range of modulation indexes. Similarly to previous methods, the overshoot period can be maintained constant and variable.

In third harmonic injection constant boost technique the sinusoidal reference signal is merged with third harmonic sinusoidal waveforms with one third amplitude of the fundamental, to generate non-sinusoidal waveforms. Constant shoot-through is introduced in zero states by comparing the triangular carrier wave with a positive, negative constant magnitude and generated non-sinusoidal sinusoidal reference waveforms as in simple boost control. The gate pulses are shown in Figure 4.

Further, variable shoot-through times are provided considering the third harmonic injected sinusoidal reference waveforms and triangular carriers like maximum boost control. The gate pulses are shown in Figure 5. 


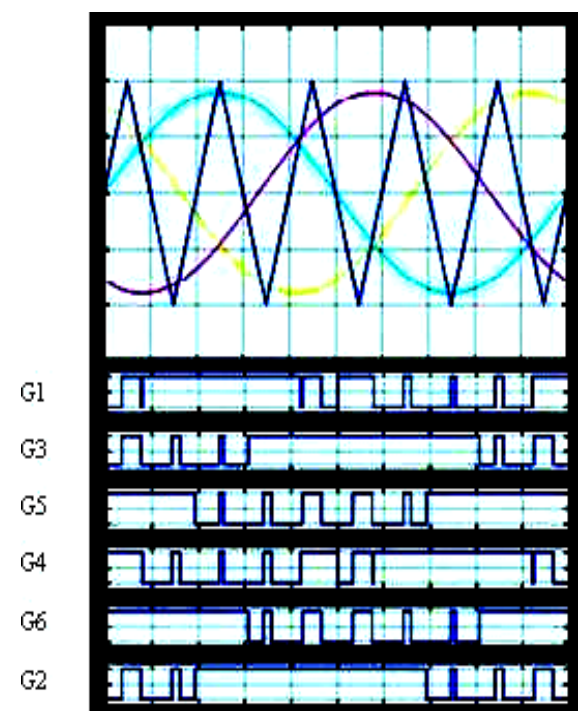

Fig. 3. Gate pulse of maximum boost ZSI

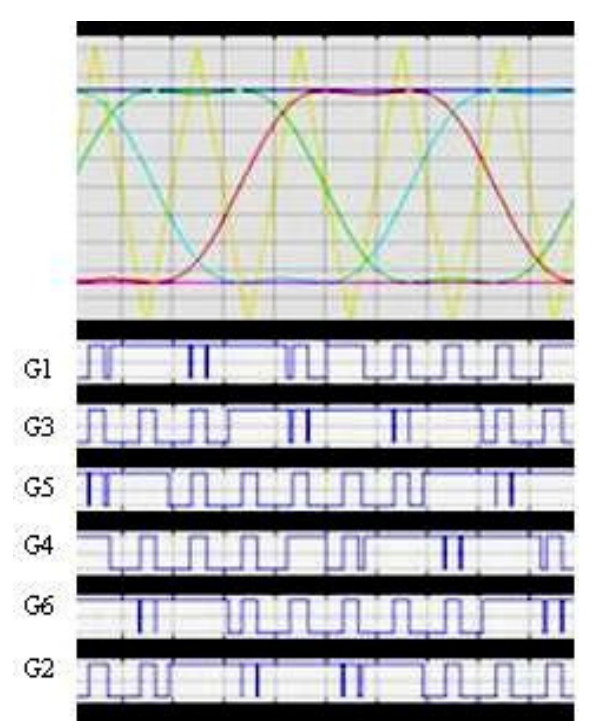

Fig. 4. Gate pulse for third harmonic injected constant boost ZSI

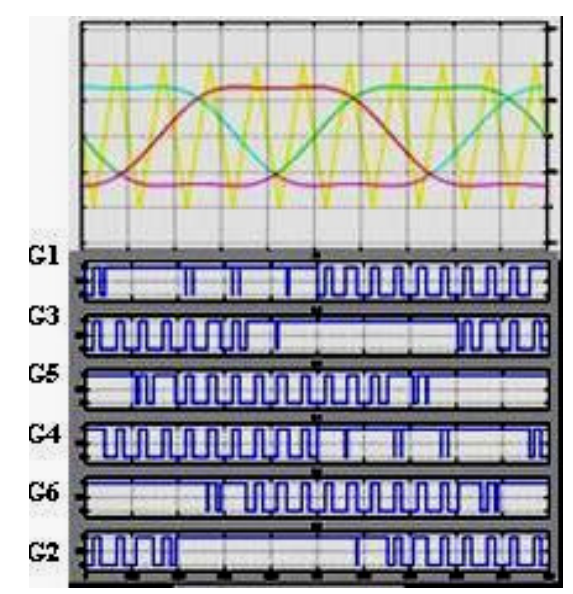

The average boost factor and voltage gain in the above two cases [2] are given as follows:

$$
\begin{aligned}
& B=\frac{1}{1-\frac{2 T_{o} / T}{T}}=\frac{\pi}{3 \sqrt{3} M-\pi} \\
& G=M B=\frac{\hat{V}_{a c}}{V_{o} / 2}=\frac{\pi M}{3 \sqrt{3} M-\pi} \\
& V_{s}=B V_{o}=\frac{3 \sqrt{3} G-\pi}{\pi} V_{o}
\end{aligned}
$$

The voltage gain remains the same as in the maximum boost control, so voltage stresses also remain the same. The only advantage in harmonic injected methods is the use of large range modulation indexes $(M)$.

\section{PERFORMANCE ANALYSIS}

MATLAB simulations were performed to verify and compare different control methods. The SIMULINK model used is shown in Figure 6. The parameters used are: $\mathrm{L}_{1}=\mathrm{L}_{2}=0.5$ $\mathrm{mH}, \mathrm{C}_{1}=\mathrm{C}_{2}=2 \mathrm{mF}, \mathrm{V}_{0}=100 \mathrm{~V}$ (DC), Switching frequency=2 $\mathrm{kHz}$, Load: $\mathrm{R} /$ phase $=50 \mathrm{ohm}, \mathrm{L} /$ phase $=2 \mathrm{mH}$. The purpose of the system is to compare the performance of the different control techniques under different modulation indexes with constant DC voltage input. A comparative analysis of voltage gain at different $M$ is performed based on the mathematical calculation and simulation result for various control techniques. Results are shown in Figures 7-10. The simulation results for voltage gain mostly matches the theoretical analysis, which verifies the above analysis and control concepts.

The comparative bar graph in Figure 11 for per unit output voltage at different modulation index shows the boosting of voltage with respect to VSI. Table I and the bar graph shown in Figure 12, compares the \%THD of output voltage at selected modulation indexes for various control methods of ZSI with VSI. THD in different boosting methods is a little higher in comparison to VSI, but their ranges are within the permissible limit. The maximum boost control technique yields higher \%THD in comparison to constant boost technique.

TABLE I. \%THD COMPARISON OF OUTPUT VOLTAGE.

\begin{tabular}{|c|c|c|c|c|c|}
\hline $\begin{array}{c}\text { Mod. } \\
\text { Index }\end{array}$ & \multicolumn{5}{|c|}{ \%THD in Different inverters } \\
\hline & VSI & $\begin{array}{c}\text { Simple } \\
\text { Boost }\end{array}$ & $\begin{array}{c}\text { 3 h } \\
\text { Const. } \\
\text { boost }\end{array}$ & $\begin{array}{c}\text { Max. } \\
\text { boost }\end{array}$ & $\begin{array}{c}\text { 3h } \\
\text { max. } \\
\text { boost }\end{array}$ \\
\hline 0.65 & 0.32 & 1.38 & 0.62 & 2.2 & 1.95 \\
\hline 0.7 & 0.29 & 1.44 & 1.74 & 4.58 & 4.03 \\
\hline 0.9 & 0.23 & 0.92 & 0.78 & 4.37 & 4.48 \\
\hline 1.1 & 2.52 & 2.57 & 1.36 & 5.65 & 4.44 \\
\hline
\end{tabular}

Fig. 5. Gate pulse of third harmonic injected maximum boost ZSI 


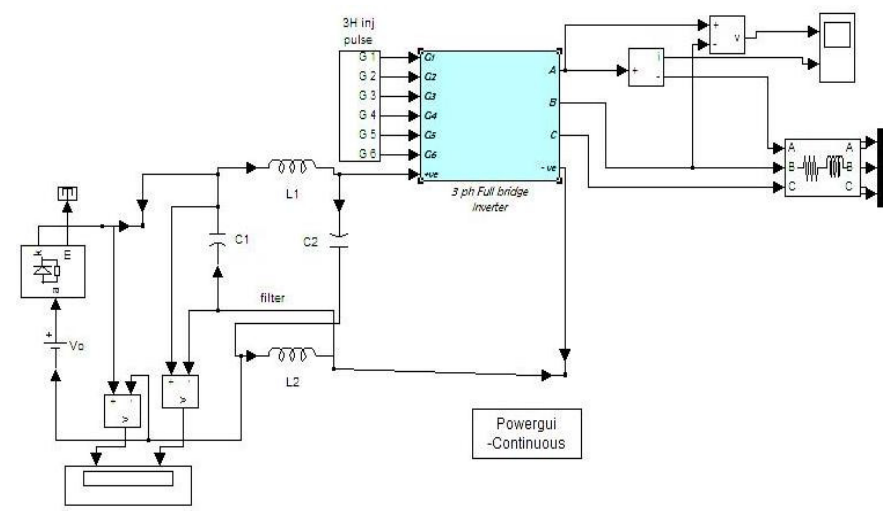

Fig. 6. Circuit diagram of ZSI

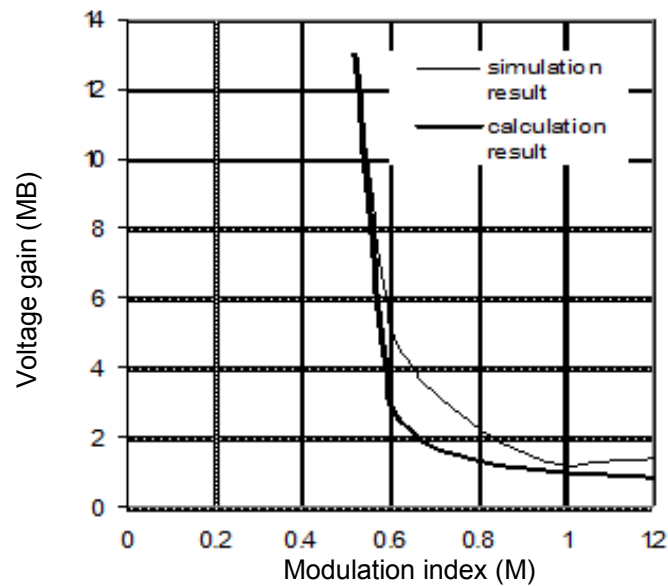

Fig. 7. Voltage gain vs modulation index comparison for simple boost control

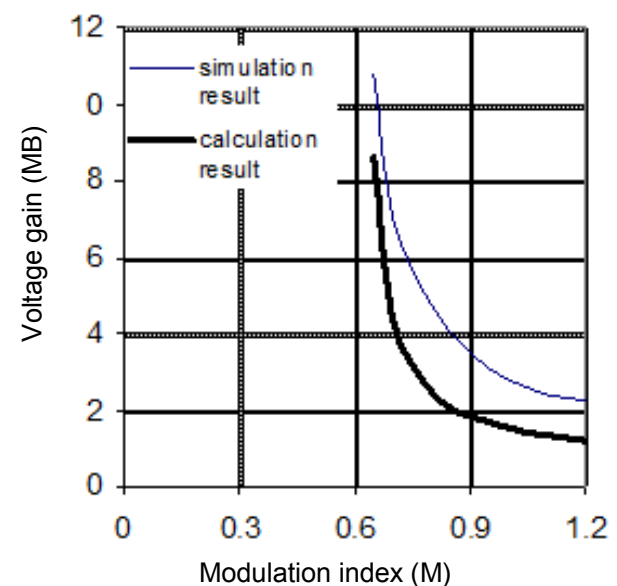

Fig. 8. Voltage gain vs Modulation index comparison for maximum boost control

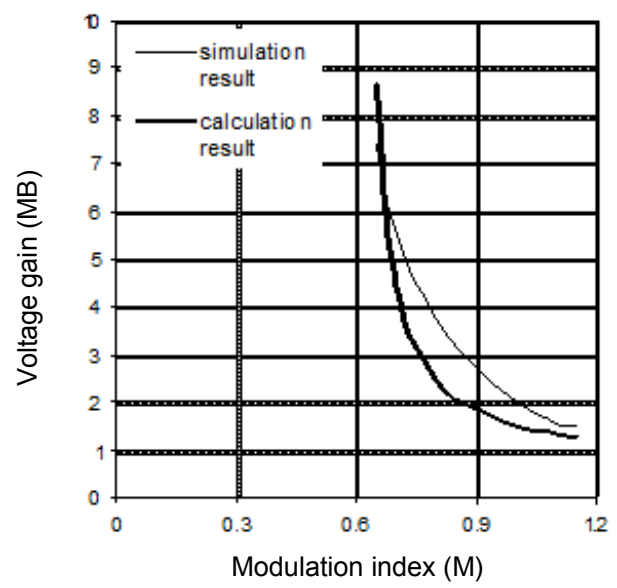

Fig. 9. Comparison of voltage gain vs modulation index for $1 / 6$ th third harmonic injected constand boost ZSI

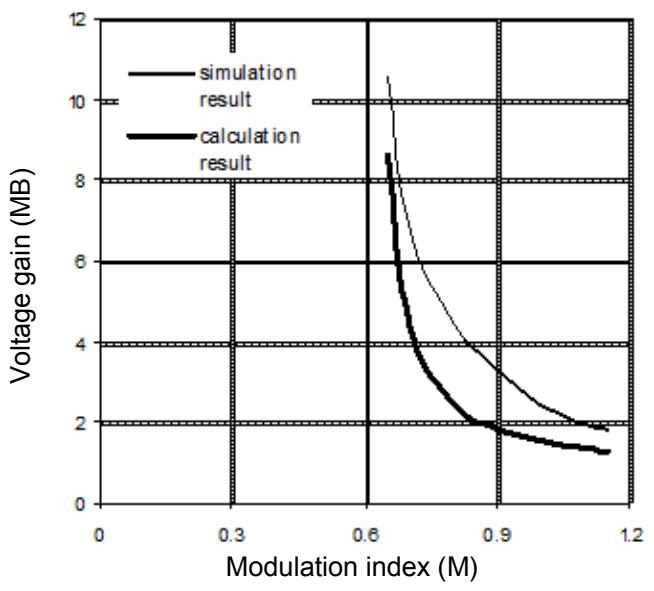

Fig. 10. Comparison of voltage gain vs modulation index for $1 / 6$ th third harmonic injected Max. boost ZSI

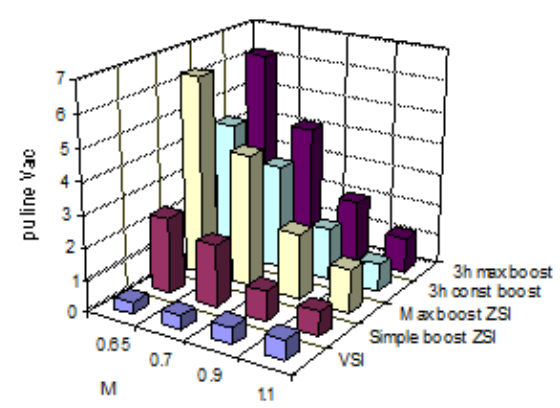

Fig. 11. pu voltage comparison of ZSI with VSI 


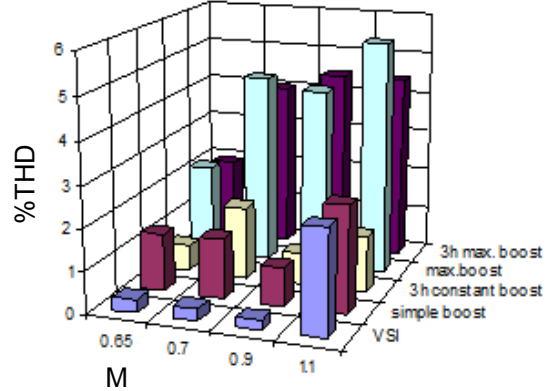

Fig. 12. Comparison of \%THD for different ZSI with VSI at different modulation index

Table II represents the comparison of \%age harmonics of output voltage for third, fifth and seventh order in different control methods at selected modulation index $(M)$. The percentage harmonics of constant boost ZSI are at par with VSI. But the seventh harmonic in maximum boost control technique is slightly higher. The simulated output voltage and current waveforms at $M=0.7$ with passive R-L load in third harmonics injected maximum boost ZSI is shown in Figure 13 for illustration.

TABLE II. $\%$ HARMONICS COMPARISON OF OUTPUT VOLTAGE.

(a) $3^{\text {rd }}$ harmonics

\begin{tabular}{|c|c|c|c|c|c|}
\hline $\begin{array}{c}\text { Mod. } \\
\text { Index }\end{array}$ & \multicolumn{5}{|c|}{ \% Harmonics } \\
\hline & VSI & $\begin{array}{c}\text { Simple } \\
\text { Boost }\end{array}$ & $\begin{array}{c}\text { 3 h } \\
\text { Const. } \\
\text { boost }\end{array}$ & $\begin{array}{c}\text { Max. } \\
\text { boost }\end{array}$ & $\begin{array}{c}\text { 3h } \\
\text { max. } \\
\text { boost }\end{array}$ \\
\hline 0.65 & 0.02 & 0.21 & 0.24 & 0.11 & 0.16 \\
\hline 0.7 & 0.01 & 0.21 & 0.09 & 0.07 & 0.05 \\
\hline 0.9 & 0.01 & 0.04 & 0.12 & 0.30 & 0.16 \\
\hline 1.1 & 0.01 & 0.33 & 0.28 & 0.14 & 0.07 \\
\hline
\end{tabular}

(b) $5^{\text {th }}$ harmonics

\begin{tabular}{|c|c|c|c|c|c|}
\hline $\begin{array}{c}\text { Mod. } \\
\text { Index }\end{array}$ & \multicolumn{5}{|c|}{ \% Harmonics } \\
\hline & VSI & $\begin{array}{c}\text { Simple } \\
\text { Boost }\end{array}$ & $\begin{array}{c}\mathbf{3} \text { h } \\
\text { Const. } \\
\text { boost }\end{array}$ & $\begin{array}{c}\text { Max. } \\
\text { boost }\end{array}$ & $\begin{array}{c}\text { 3h } \\
\text { max. } \\
\text { boost }\end{array}$ \\
\hline 0.65 & 0.02 & 0.92 & 0.39 & 1.41 & 1.10 \\
\hline 0.7 & 0.02 & 0.83 & 1.59 & 4.14 & 3.40 \\
\hline 0.9 & 0.03 & 0.42 & 0.47 & 2.68 & 3.07 \\
\hline 1.1 & 2.12 & 1.24 & 1.12 & 1.42 & 2.14 \\
\hline
\end{tabular}

(c) $7^{\text {th }}$ harmonics

\begin{tabular}{|c|c|c|c|c|c|}
\hline $\begin{array}{c}\text { Mod. } \\
\text { Index }\end{array}$ & \multicolumn{5}{|c|}{ \% Harmonics } \\
\hline & VSI & $\begin{array}{c}\text { Simple } \\
\text { Boost }\end{array}$ & $\begin{array}{c}\text { 3 h } \\
\text { Const. } \\
\text { boost }\end{array}$ & $\begin{array}{c}\text { Max. } \\
\text { boost }\end{array}$ & $\begin{array}{c}\text { 3h } \\
\text { max. } \\
\text { boost }\end{array}$ \\
\hline 0.65 & 0.24 & 0.54 & 0.24 & 1.09 & 0.96 \\
\hline 0.7 & 0.21 & 0.29 & 0.49 & 1.18 & 1.91 \\
\hline 0.9 & 0.18 & 0.17 & 0.07 & 3.07 & 2.93 \\
\hline 1.1 & 1.33 & 1.62 & 0.31 & 5.07 & 3.56 \\
\hline
\end{tabular}
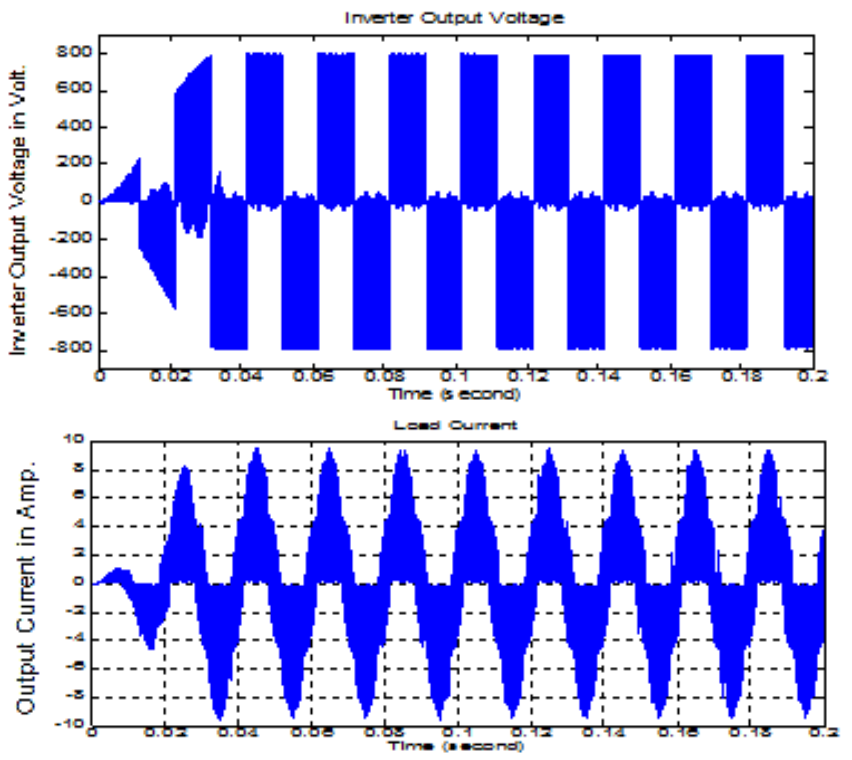

Fig. 13. Simulated results of load line voltage and load current

\section{CONCLUSION}

This paper compares the performances of the control methods of ZSI to achieve the maximum voltage output within the prescribed limit of harmonics and THD percentages. The method can achieve the minimum passive component requirement and maintain low voltage stress at the same time. This method can be suitable for controlling voltage sags and swells in drives.

\section{REFERENCES}

[1] F. Z. Peng, "Z-source inverter", IEEE Transactions on Industry Applications, Vol. 39, No. 2, pp. 504-510, 2003

[2] F. Z. Peng, M. Shen, Z. Qian, "Maximum boost control of the Z-source inverter", IEEE Transactions on Power Electronics, Vol. 20, No. 4, pp. $833-838,2005$

[3] P. C. Loh, D. M. Vilathgamuwa, Y. S. Lai, G. T. Chua, Y. Li, "Pulsewidth modulation of Z-source inverters", IEEE Transactions on Power Electronics, Vol. 20, No. 6, pp. 1346-1355, 2005 